\title{
A fatal case of cerebral abscess due to Nocardia asteroides
}

\author{
S. I. JACOBS AND R. MYLES GIBSON \\ From the Department of Neurosurgery, General Infirmary at Leeds
}

Nocardia asteroides, an aerobic acid-fast organism which produces a true fragmenting mycelium, was first isolated by Eppinger (1890) from a brain abscess and given the name Cladothrix asteroides. Since then it has been known variously as Streptothrix eppingeri and Actinomyces asteroides but the name in current use is that suggested by Blanchard (1896). The organism, which causes the rare disease of nocardiosis is a natural inhabitant of the soil. Ballenger and Goldring (1957) scrutinized the world literature and listed 95 reports of the disease, but in a review Peabody and Seabury (1957) consider only about 50 cases to be authentic. Doubt arises in many other cases because either the organism has not been adequately described or there is insufficient proof of its primary pathogenic role.

In man the lungs are the site of primary attack, but several atypical cases have been described in which there was no apparent pulmonary involvement. The disease may remain confined to the lungs or spread throughout the body via the blood stream. The sites most frequently secondarily infected in this way are the subcutaneous tissues and the central nervous system, the latter being involved in one-third of all cases. Up to 1954 Krueger, Norsa, Kenney, and Price accept 19 such cases although Ballenger and Goldring list some 21 cases. After 1954, the latter list catalogues a further 10 and since that time two more (Erchul and Koch, 1955; Hiddlestone, 1957) have been described in the English literature making 33 in all. A further six cases have been found in the literature of France, Belgium, Italy, Serbia, and Poland.

The case to be reported, one of cerebral abscess with secondary meningitis due to Nocardia asteroides, is the first to be described in Great Britain for over 50 years; the last case of nocardial disease of the central nervous system was reported by McDonald in 1904. It is also one of the few to have been diagnosed bacteriologically before death. In view of the poor prognosis of intracranial nocardiosis which may, however, be influenced by early recognition and appropriate radical treatment, additional experiences should be recorded.

\section{CASE HISTORY}

The patient was a man, aged 55 years, employed as a long distance lorry driver. For many years he had suffered from a cough and latterly from dyspnoea on exertion.

He was admitted to the General Infirmary at Leeds on 28 April 1958 under the care of Dr. R. N. Tattersall with a history of a local attack one week previously consisting of weakness, stiffness, and numbness of the left arm. It occurred while he was washing his hands, and was of short duration. He had a second similar attack on the morning of his admission to hospital. There were no other symptoms. On admission to hospital he was apathetic but fully cooperative and well orientated. The fundi were normal. There was a mild diffuse weakness of the left arm but no sensory impairment. His gait was slightly spastic and both plantar responses were extensor. There were no other abnormal neurological signs and findings on lumbar puncture were normal.

After five days in hospital, as he had had no further attacks, he was discharged home and arrangements were made to follow him up as an out-patient. Four days later, however, he was readmitted as an emergency because of repeated local epileptic attacks involving the left limbs. There was no loss of consciousness and the attacks were controlled by intramuscular phenobarbitone. During the course of the next week he became drowsy and at times even stuporose and was transferred to the Neurosurgical Unit.

By this time there was paralysis of the left arm and marked generalized weakness of the left leg. Both legs were mildly spastic, the right more so than the left, and both plantar responses were extensor. The fundi were normal. His level of consciousness did not permit a more detailed neurological examination but it was noted that the patient had a frequent productive cough.

A chest radiograph showed slight segmental atelectasis of the right lower zone but no evidence of neoplasm. The skull radiographs showed no abnormality; the pineal gland was not calcified.

The attacks of disability involving the left limbs, which occasioned his first admission to hospital, had suggested a possible diagnosis of vascular insufficiency or occlusion. The later clinical state suggested a spaceoccupying lesion involving the right cerebral hemisphere. Spasticity of both legs and bilateral extensor plantar responses indicated brain-stem ischaemia, the result of the brain-stem being displaced by a supratentorial right-sided space-occupying lesion. 
Right carotid angiography under local anaesthesia showed that the anterior cerebral artery was slightly displaced to the left. The middle cerebral artery was displaced downwards and the vessels in the parietal region were stretched. These findings confirmed the presence of a space-occupying lesion in the right parietal region and an immediate exploratory operation was carried out on May 15.

Under local anaesthesia, a burr hole was made in the right parietal region and the brain explored with a brain cannula. At a depth of $3.5 \mathrm{~cm}$. about $12 \mathrm{ml}$. of greenish-yellow pus was found. No capsule was felt and the abscess appeared to be surrounded only by soft oedematous brain. Thorotrast, $1 \mathrm{ml}$, and chloramphenicol, $1 \mathrm{ml}$., were introduced into the abscess cavity and the wound closed.

Following this aspiration the patient's level of consciousness improved and he was now able to cooperate in further neurological examination which showed that there was also a left homonymous hemianopia, hypalgesia of the left limbs, together with loss of position sense in the left arm and left toes. Three days later the abscess was re-aspirated and $4 \mathrm{ml}$. of pus obtained but the improvement following the initial tapping was not maintained and the patient relapsed into his previous drowsy, apathetic state.

An organism which resembled $N$. asteroides in morphology, cultural characteristics, and pathogenicity for laboratory animals and chick embryos was isolated from the pus obtained at the first aspiration. The identity was subsequently confirmed by Dr. Jacqueline Walker of the London School of Tropical Medicine and Hygiene. It was isolated again on two subsequent occasions (Fig. 1) from aspirated material in pure culture, and in consequence the therapeutic régime was changed to include sulphadiazine and streptomycin.
Subsequent radiographs of the skull showed the abscess cavity to be shrinking and only a small quantity of sanguinous fluid could be obtained on aspiration. However, the surrounding brain felt very soft and oedematous.

The patient's productive cough became much worse in the post-operative period and tracheotomy was performed on 1 June to facilitate the tracheo-bronchial toilet. On 3 June a monilial superinfection of the sputum was noted and he developed thrush in the mouth. Nystatin was given topically by aerosol and by gastric tube but there was no improvement in either the chest condition or the hemiplegia and he gradually deteriorated and died on 2 July.

NECROPSY The salient findings were as follows. The lungs (distended with formalin) showed a widespread mild bronchiolectasis, chronic bronchitis, and in the lower lobes foci of bronchopneumonia. There was a small abscess $(1 \mathrm{~cm}$. in diameter) in the anterior segment of the left upper lobe, with a thin fibrous wall, and creamy contents (Fig. 2). The stomach showed six small acute erosions of the mucosa. The right knee joint contained some light brown transparent fluid and its synovial membrane was slightly thickened. The brain was fixed by carotid perfusion. It showed a marked cerebellar pressure cone, and the site of a needle entrance in the right superior postcentral cortex. The meninges in the posterior fossa, but particularly over the ventraf surface of the pons and medulla, were slightly thickened and bespattered with a relatively small number of small yellowish-white nodules $1-3 \mathrm{~mm}$. in diameter, resembling tubercles. On coronal section there was a large absces\}్ in the white matter of the right parietal region, $3 \mathrm{~cm}$. vertically, $2.3 \mathrm{~cm}$. laterally, and $2.0 \mathrm{~cm}$. antero-posteriorly In places it was surrounded by a thin translucent bandlike a capsule but in other places the pale pus waș

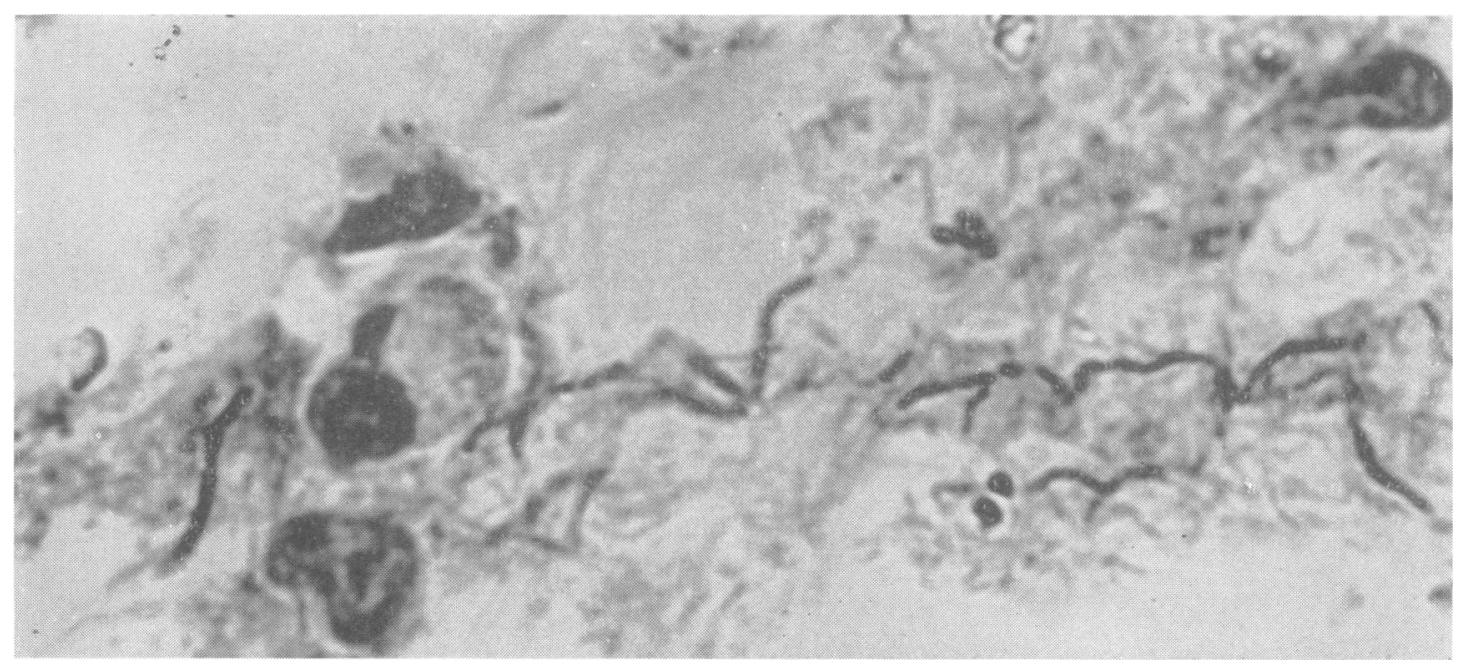

FIG. 1. Section of chick embryo membrane showing organisms branching and ramifying. Note beaded appearance of organism. Gram $\times 2,000$. 


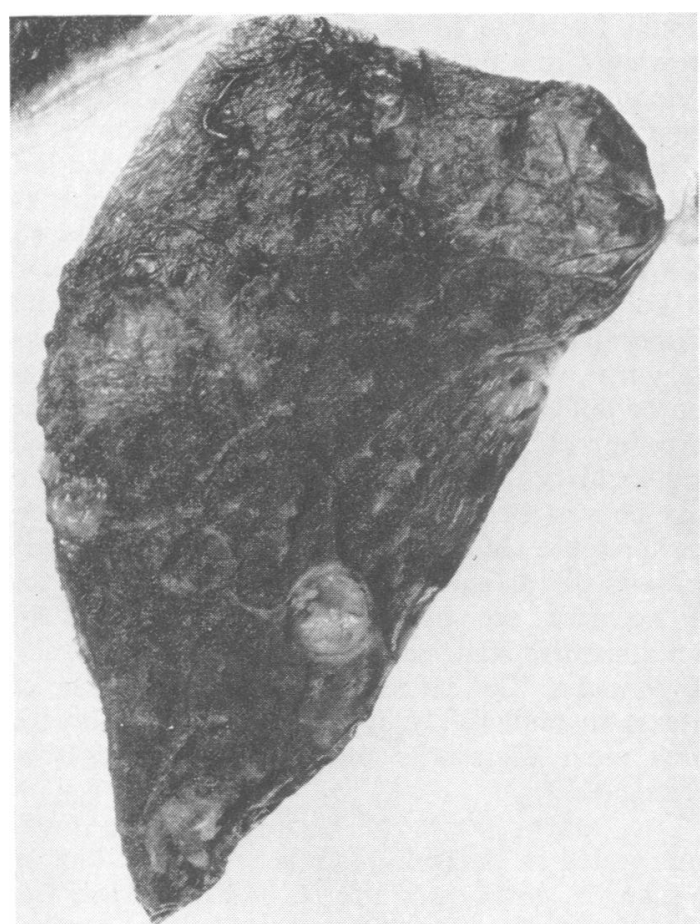

FIG. 2. Small abscess in anterior segment of upper lobe of left lung (about half natural size).

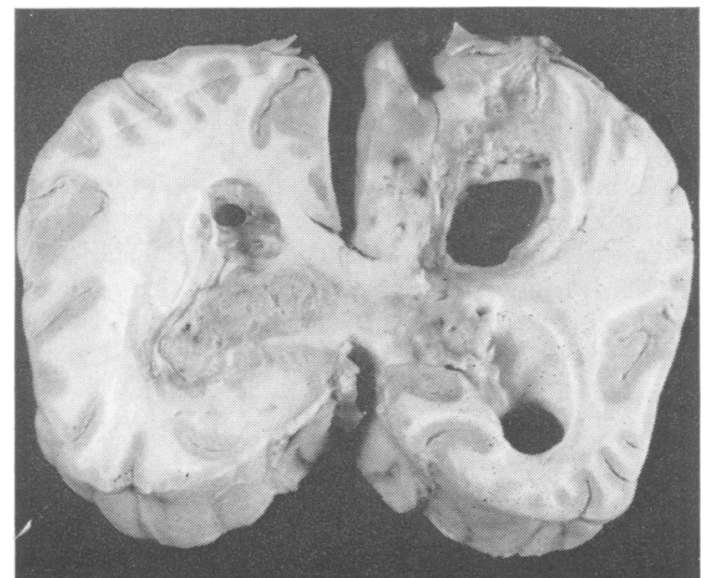

FIG. 3. Abscess in right parietal white matter and multiple choroidal abscesses.

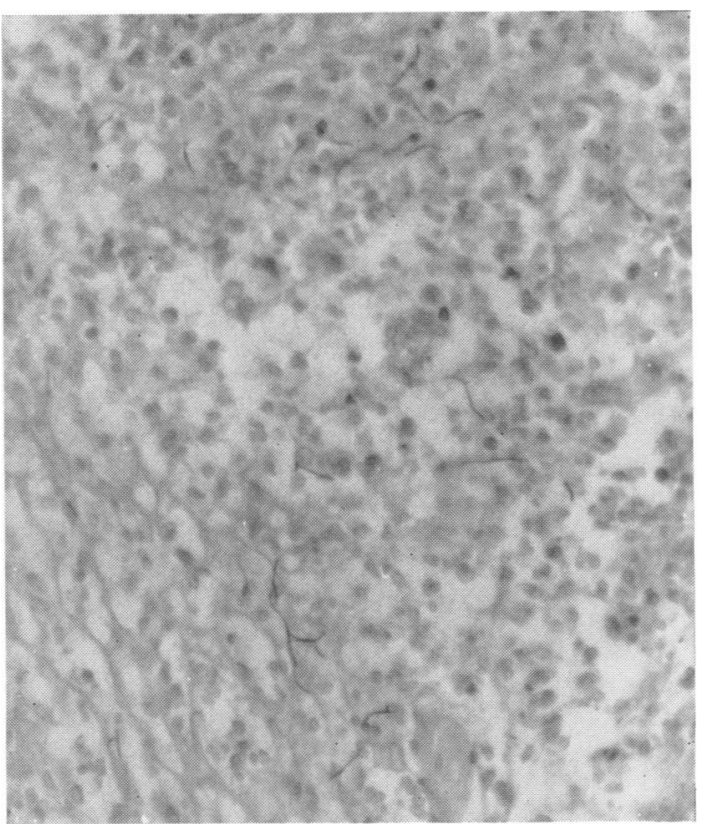

FIG. 4. Branching organisms within the parietal abscess. Gram stain $\times 400$.

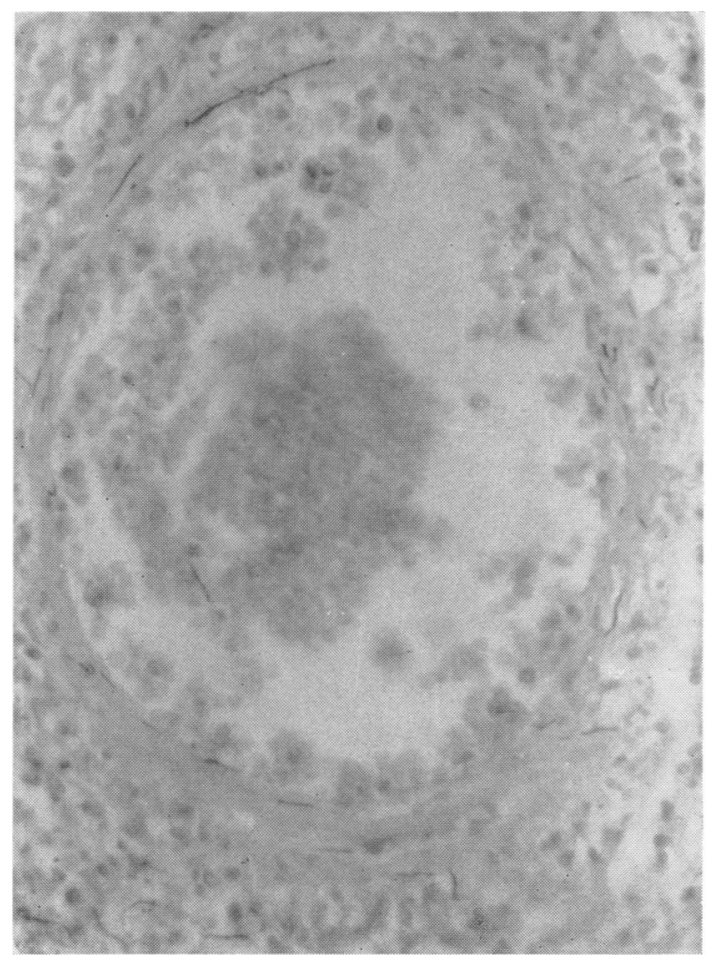

FIG. 5. N. asteroides within the wall of a meningeal vein. Gram stain $\times 400$. 
bordered directly by white matter. The abscess extended by a broad irregular tract of pus to the surface at the biopsy site. In addition to the right parietal abscess, the choroid plexus of the lateral ventricles was extensively involved by suppuration, many small confluent abscesses being formed (Fig. 3). An obstructive mass was found in the trigone of the left lateral ventricle, and spread forwards beneath the fornix in the bodies of both lateral ventricles.

HISTOLOGY Blocks were embedded in paraffin and stained by the routine methods including Gram's stain and Ziehl Neelsen stain for organisms.

The large abscess in the right parietal region was not capsulated in the manner of the usual bacterial abscess. It consisted of a central mass of pus but towards the edge individual although coalescent suppurative foci could be made out. Each of these was bordered by a few epitheloid and multinucleate giant cells, intermingling with fibroblasts and proliferating capillaries in small numbers. A Gram stain revealed many branching organisms in the pus (Fig. 4).

The same picture was obtained in the ventricle, where the choroid contained many abscesses of similar structure.

In the meninges over the base of the brain the granulomata seen with the naked eye consisted again of foci of suppuration with attendant giant cell and fibroblastic reactions, and there was in addition a diffuse infiltration by mononuclear cells and polymorphs. Many small blood vessels, both arterial and venous, showed changes due to inflammation. Some small veins were filled with pus and fibrin clot and their walls were infiltrated by polymorphs and mononuclear cells. The arteries showed similar mural infiltration and fibrous endarteritis. The vascular involvment was due directly to invasion of the vessel walls by the filamentous branching organisms (Fig. 5).

The lung abscess was of banal appearance, the central pus being walled off by simple vascular fibrous tissue. Small clumps of unidentifiable cocci were present in the wall and in the pus but no branching organisms were found, nor were there any large colonies.

\section{DISCUSSION}

Since nocardiosis responds to a different therapeutic régime from that effective in the treatment of classical actinomycosis it is imperative that an early and accurate diagnosis be made. In the period 1890 to 1945 only eight cases of nocardial infection of the central nervous system were recognized but in the last 14 years that number has increased four-fold. This may indicate that the disease is becoming more prevalent, or more likely, that it is recognized more often. It is possible that the organism is frequently thought to be a contaminant and its presence in cultures disregarded as happened in the first instance in this case. When nocardial disease is considered, the bacterial diagnosis can be made in any laboratory, and the possibility should be borne in mind whenever an organism growing with a fragmenting mycelium is isolated.

Because growth of the organism takes place under aerobic conditions classical actinomycotic infection can be excluded. Being partially acid-fast the organism may be considered to be a member of the family of mycobacteriaceae but the diagnosis of $M$. tuberculosis is excluded when growth is found to be rapid and on simple media. Furthermore neither pathogenic nor saprophytic mycobacteria show true, well-defined branching. The streptomyces can be differentiated from the nocardia because the mycelium of the latter readily fragments into coccal and bacillary forms, so much so that the organism may be mistaken for a corynebacterium. However, the presence of true branching elements again excludes this diagnosis. Only two pathogenic species of nocardia are listed in Bergey's Manual of Determinative Bacteriology (1957), N. asteroides and $N$. faranica. The latter is essentially a cause of disease in animals, being the organism of bovine farcy, and it differs in its cultural characteristics from $N$. asteroides.

Two other species of nocardia besides those enumerated in Bergey's Manual may cause disease in man, $N$. brasilienses and $N$. intracellularies. Thष first is largely limited to Central and South America市 음 though two cases of disease caused by this organism have occurred in the United States (Moore, Lane and Gaul, 1954; Bobbitt, Friedman, and Luptons 1955). The latter is a newly recognized species which was isolated from the lymph nodes, spleen, livere and colon of a 34-month-old child (Cuttino and McCabe, 1949), and is apparently an obligate intracellular parasite.

Although $N$. asteroides was not demonstrated in the lung abscess in this case, the abscess was the probable site of its entry into the body, with subsequent spread by the blood stream. To the pathologist, a problem may arise when a cerebral abscess is discovered at biopsy or necropsy without any evidence of the causative organism. At necropsy, the naked-eye appearance which helps to differentiate a nocardial from a pyogenic abscess is the lack of any capsule and the confluence of small suppurative foci. This may also occur in many fungal and parasitic infections, all of them rare in Great Britain, and accurate diagnosis depends on culture. Gram's stain in both biopsy and necropsy specimens may show the branching organism in nocardiosis. Some nocardial cerebral abscesses may escape diagnosis through lack of histological examination, so that the condition may not be as rare as it appears to be at present.

One interesting histological feature in the present case is the invasion of vascular walls by the organism. 
This detail is undoubtedly of importance in the spread of the disease, but appears to have escaped attention in the majority of case reports (Weed, Andersen, Good, and Baggenstoss, 1955; Turner, 1954; Bernstein, Cook, Plotnick, and Tenczar, 1962; Ballenger and Goldring, 1957). Vascular invasion by organisms is of course not new, and has been recognized since it was demonstrated in Heubner's syphilitic arteritis.

Little is known about the neurological aspects of nocardiosis even though in 56 accepted cases the central nervous system was involved in 19 (Krueger et al., 1954) and it often appeared to be responsible for the fatal outcome. Infection of the central nervous system has been described at all ages between 15 months and 65 years and it takes the form of brain abscesses, with meningitis as a later complication, but occasionally meningitis occurs without abscess formation. The neurological symptoms and signs tended to develop several months after the onset of extraneural manifestations, and were related to the site of infection within the brain and to raised intracranial pressure. In almost all cases with central nervous system disease on which a post-mortem examination has been performed additional visceral lesions were found, usually in the lungs and subcutaneous tissues.

Only occasional cures of nocardial brain abscess have been reported (Krueger et al., 1954; Munslow, 1954; List, Williams, Beeman, and Payne, 1954). It appears that successful treatment of cerebral nocardiosis requires surgical removal of the focus or foci in the brain together with extremely vigorous and prolonged chemotherapy. Simple drainage is ineffective due to the multilocular character of the abscesses, the absence of capsulation, and the prolific growth of the organism. Sensitivity testing of the organism in vitro has yielded very variable results and is of little help in determining treatment. Treatment with sulphadiazine and streptomycin in vivo has been the most satisfactory régime, but in recent reports numerous antibiotics have been tried, usually without success.

\section{SUMMARY}

A fatal case of cerebral nocardiosis is described and the clinical, bacteriological, and pathological aspects of the disease discussed. The importance of early and accurate diagnosis is emphasized to ensure the most satisfactory clinical management, and the need for radical and intensive treatment is stressed.

Our thanks are due to Dr. R. N. Tattersall and $\mathrm{Mr}$. A. E. Wall for permission to submit this report, to Dr. G. N. Williamson and Dr. C. P. J. La Touche for help with the bacteriological aspects of the case, to Professor Norman Dott, F.R.S., and Professor C. L. Oakley, F.R.S., for their advice, and to the Calmic Research Fund.

We are indebted to Dr. D. G. F. Harriman for the necropsy and histological studies.

\section{REFERENCES}

Ballenger, C. N., and Goldring, D. (1957). J. Pediat., 50, 145.

Bergey, D. H. (1957). Manual of Determinative Bacteriology, 7th ed. Ballière, Tindall and Cox, London.

Bernstein, I. L., Cook, J. E., Plotnick, H., and Tenczar, F. J. (1962). Ann. intern. Med., 36, 852.

Blanchard, R. (1896). In Traité de Pathologie Générale, edited by C. Bouchard, vol. 2, p. 811. Masson, Paris.

Bobbitt, O. B., Friedman, I. H., and Lupton, C. (1955). N. Engl. J. Med., 252, 893.

Cuttino, J. T., and McCabe, A. M. (1949). Amer. J. Path., 25, 1.

Eppinger, H. (1890). Wien. klin. Wschr., 3, 321.

Erchul, J. W., and Koch, M. L. (1955). Amer. J. clin. Path., 25, 775. Hiddlestone, H. J. H. (1957). N. Z. med. J., 56, 399.

Krueger, E. G., Norsa, L., Kenney, M., and Price, P. A. (1954). J. Neurosurg., 11, 226.

List, C. F., Williams, J. R., Beeman, C.B., and Payne, C. A. (1954). Ibid., 11, 394.

McDonald, S. (1904). Scot. med. surg. J., 14, 305.

Moore, M., Lane, C. W., and Gaul, L. E. (1954). A.M.A. Arch. Derm. Syph., 70, 302.

Munslow, R. A. (1954). J. Neurosurg., 11, 399.

Peabody, J. W., and Seabury, J. H. (1957). J. chron. Dis., 5, 374.

Turner, O. A. (1954). J. Neurosurg., 11, 312.

Weed, L. A., Andersen, H. A., Good, C. A., and Baggenstoss, A. H. (1955). N. Engl. J. Med., 253, 1137. 